\title{
A REPRESENTAÇÃO ESCRITA DE RUÍDOS E DE AÇÕES EM CHARGES E EM HISTÓRIAS EM QUADRINHOS
}

\author{
How noises and actions are written in comics and charges
}

\author{
Luiz Carlos CAGLIARI \\ Universidade Estadual de Campinas \\ lccagliari@gmail.com
}

\begin{abstract}
RESUMO: Os sistemas de escrita escrevem palavras fixadas pela ortografia. Contudo, mesmo tendo uma forma ortográfica, as interjeições dificilmente são aceitas como palavras iguais às demais que constam dos dicionários. As interjeições são representações onomatopaicas de sons, ações e de sentimentos. Mas, as interjeições não são suficientes para essa finalidade, fazendo com que surjam onomatopeias mais ou menos à vontade dos escritores e dos artistas. Uma vez que o uso dessas formas de escrita tem sido disseminado ao longo da história literária e, mais recentemente, em charges, HQs e através da Internet, podemos reconhecer uma tradição no uso de certas palavras desse tipo. Um estudo linguístico desse problema mostra a natureza, as funções e os usos dessas palavras onomatopaicas e de palavras que se referem a sons, ruídos, ações e sentimentos em contextos especiais onde encontramos também desenhos, como nas charges e nas HQs. PALAVRAS-CHAVE: Histórias em Quadrinhos; Charges; Escrita; Interjeição; Sons; Ações.
\end{abstract}

\begin{abstract}
Writing systems transcribe words that have been fixed by orthography. However, even with an orthographic form, the interjections are hardly accepted as words similar to others in the dictionary. They are onomatopoeic representations of sounds, actions and feelings. But interjections are not satisfactory causing the invention of other onomatopoeic words, created somehow at will by writers and artists. Because their use have disseminated along the literary history and recently in special in charges, HQ and in the Internet, we can recognize the fact that most of them became traditional representations of speech. A linguistic view of the problem show the nature, the functions and the uses of these onomatopoeic words and words referring to sounds, noises, actions and feelings in special contexts where we find also drawings, as in charges and HQs. KEYWORDS: Comics; Charges; Writing; Interjections; Sounds; Actions.
\end{abstract}




\section{INTRODUÇÃO}

Um problema tradicional das gramáticas é reconhecer ou não as interjeições e onomatopeias como palavras da língua. Um dos motivos fortes para a não aceitação reside no fato de algumas interjeições e onomatopeias terem uma estrutura fonética com sons que não podem ser aceitos como fonemas e como estruturas fonológicas. Por exemplo, uma forma de negação em Português é dita com duas sílabas iguais formadas com cliques nasais alveolares surdos (CAGLIARI, 2007, p. 24-26).

Joãozinho mexendo em coisas que ele não devia...

Mãe: Nuht! Nuht! Não pode mexer!...

Dingemanse, Torreira e Enfield (2013) escreveram um trabalho interessante, investigando como várias línguas usam uma "interjeição" (huh?; huh!) (hã?; hã-hã!) para o ouvinte se manifestar numa conversa, perguntando ou afirmando. Segundo os autores, essa interjeição seria uma espécie de palavra universal, encontrada em todas as línguas. Apesar disso, essa palavra não costuma vir dicionarizada. Os autores chegam à conclusão de que Huh? é universal e que se trata de uma palavra como qualquer outra da língua. O problema, na verdade, está na definição semântica do que seja uma palavra. Essa "interjeição" ou "expressão", como apontam os autores, tem vida num contexto pragmático de processo interativo específico, ou seja, em conversas. Além disso, teria um uso marcado, indicando uma quebra da comunicação na pergunta e uma necessidade de conserto para que a conversa possa continuar. No modelo apresentado pelo autor, podemos inventar um exemplo:

Pedro: Depois de anos, eu fui à casa da Ana...

Maria: Ah?!

Pedro: À casa da Ana, minha tia.

Maria: Hã-hã!

A discussão se volta para questões antigas como o reconhecimento de sons como pertencentes à linguagem e sons produzidos pelo aparelho fonador, motivados por fatos não linguísticos, por exemplo, quando alguém tosse ou chora. Alguém poderia argumentar que um gesto poderia desempenhar a mesma função nos mesmos contextos e, nem por isso, deveríamos considerá-lo uma "palavra", embora pudesse ser "universal".

Essa questão motiva uma interessante discussão: certamente, há argumentos a favor 
de uma língua com um núcleo mais linguístico e outro mais pragmático, ambos convergindo para um processo de comunicação mais abrangente e mais prático, principalmente, em se tratando de conversação, em que o processo depende de uma interação comunicativa entre interlocutores. Do ponto de vista das expectativas comunicativas (CAGLIARI, 2016), expressões como Huh? significam que o interlocutor não entendeu ou não gostou do que ouviu.

Um critério tradicional diz que uma sequência de sons orais forma uma palavra se estiver dicionarizada. Obviamente, este não é um critério científico. Partindo do conceito saussuriano de signo (SAUSSURE, 1999) como menor unidade morfológica, além da sequência de sons identificáveis pelo alfabeto fonético internacional (IPA), ou seja, suscetíveis de uma transcrição fonética, é necessário que essa sequência tenha um significado linguístico. Este último critério é de difícil identificação como no caso das interjeições e das onomatopeias. É por isso que, muitos linguistas tradicionais não consideram as interjeições e onomatopeias como palavras da língua, iguais às demais. Consideram tais eventos como ruídos que ocorrem juntamente com a fala, denotando atitudes do falante e que alguns escritores resolveram transpor para seus textos. Mas, obviamente, nem todos os ruídos produzidos pelo mecanismo da fala têm interessado os dicionaristas, os gramáticos, os linguistas ou os escritores. Uma tradição de uso mantém algumas formas escritas dessas palavras na prática.

Outro problema também interessante é a ocorrência de desenhos e de ilustrações usados para facilitar a leitura ou mesmo para torná-la mais agradável. Muitas pessoas têm uma reação um tanto negativa quando se veem diante de um texto sem ilustração ou figura. Essa é uma das razões, entre outras, pela qual em quase tudo o que se publica podem ser encontradas ilustrações para ajudar como os autores gostariam de ser interpretados. Mudar as ilustrações de uma obra pode causar danos na maneira como os leitores interpretaram as obras com as ilustrações originais. Por exemplo, as obras de Monteiro Lobato têm uma ilustração original que definiu para muitas gerações como seria a Dona Benta, O Visconde de Sabugosa, Pedrinho, Emília, entre outros. Reler essas obras com outras ilustrações pode ser chocante para quem conhecia a obra na versão antiga. A televisão e o cinema tiveram que inventar através de pessoas reais os personagens do Sítio do Picapau Amarelo (MONTEIRO LOBADO; 1920-1947). É uma leitura um pouco diferente das obras de Monteiro Lobato. Maurício de Sousa (1959 - A Turma da Mônica) também usou pessoas reais para caracterizar seus personagens das revistas em quadrinho. Mas, nada ganha dos desenhos originais.

As revistas em quadrinhos, também conhecidas como HQ (Comics nos Estados 
Unidos) são obras que contam histórias através de desenhos em sequências de quadros. Os personagens das HQs já passaram para o cinema, sendo incorporados por pessoas reais, como nos filmes da Marvel de Stan Lee. Quem só assistiu ao filme, por exemplo, da Mulher Maravilha, tem como ideia original o personagem do cinema. As imagens da revista original (CHARLES MOULTON, 1941) trazem detalhes e conotações que o filme deixou de fora. Por outro lado, o filme atual da diretora Patty Jenkins (2017) traz uma concepção da Mulher Maravilha que só o cinema consegue fazer. Quem começou com as revistas em quadrinhos, tem um juízo crítico favorável ou não com relação aos mesmos personagens interpretados no cinema. Assim como os livros podem ter ilustrações diferentes, os enredos dos filmes podem gerar filmes mais ou menos diferentes. A questão subjacente aqui é: O que existe além da língua no mundo da comunicação? Desde a Antiguidade, a comunicação teve como elemento central a linguagem através da língua das pessoas envolvidas. Mas, não só! Peneirando o amontoado de elemento da comunicação, sobram muitas coisas além das palavras. Sobram até palavras que podem ou não ser reconhecidas como elementos históricos de uma língua.

A publicação das revistas em quadrinhos nem sempre foi fácil, encontrando muitas opiniões contra. Todavia, logo que apareceu, o público tornou-as um sucesso que incentivou sua continuidade. Mickey Mouse foi criado em 15 de maio de 1928. O Pato Donald foi criado em 9 de junho de 1934. A Editora Abril deixou de publicar as HQ da Disney no Brasil depois de 68 anos, em junho de 2018.

A Turma da Mônica é uma revista em quadrinhos criada por Maurício de Sousa. A versão mais antiga aparece em uma tirinha de jornal em 1959. As publicações foram feitas pela Editora Abril (1970-1986), pela Editora Globo (1987-2006) e pela Panini Comics, a partir de 2007.

Hoje, a Panini Books tem assumido a publicação de inúmeras revistas em quadrinhos, inclusive as revistas Sandman de Neil Gaiman, um dos mais notáveis HQ publicado em 2018 com tradução para o português.

Isso nos leva aos tempos modernos. A comunicação digital via Internet trouxe uma nova dimensão para velhos hábitos de leitura e de escrita. Coisas que eram sagradas como a estrutura de um texto tornaram-se menos importantes agora, sendo substituídas por ícones e por formas novas de referência comunicativa. A estrutura de um texto discursivo nas redes sociais tanto pode aparecer na forma gramatical tradicional, quanto por sequências de ícones, de emoticons, emojis, minions, de desenhos e imagens. No aplicativo WhatsAPP, sentenças se misturam com emojis e, às vezes, a informação é montada à moda de uma sentença, trazendo apenas representações pictográficas dos 
emojis em lugar das palavras escritas. Diante de tais manifestações, a compreensão da mensagem só se revela quando traduzida em linguagem do sistema linguístico do leitor, o que o obriga a compartilhar com o autor o significado que encontra. No Facebook e no WhatsApp, a sintaxe das frases, algumas vezes, depende mais da interpretação do leitor do que da gramática da língua.

Nas charges, nas tirinhas e nas histórias contadas nas HQ, o procedimento de apresentação do material é diferente do que se vê nas redes sociais (Facebook, WhatsAPP, Blogs, Sites, Grupos de Mensagem...). Nas revistas em quadrinhos, e em alguns tipos de publicações como as charges e as tiras de jornal, além de algum tipo de informação em forma de palavras e de frases comuns da língua, é comum aparecer escritas que se referem a ruídos ou a sentimentos. O cenário é semelhante ao das redes sociais atuais, mas a forma de apresentação é diferente. As redes sociais não usam balões, que são escritas ou desenhos circundados e indicando uma fala (ponta de flecha) ou algum pensamento (balão com sequência de bolinhas).
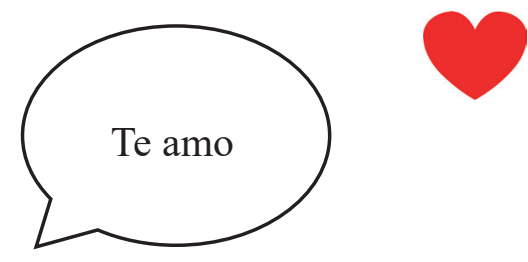

Quando os balões apareceram, vieram abrir um novo espaço na arte tipográfica, liberando escritas não ortográficas e modos não convencionais de representação de escrita e de ícones. Segundo Rodrigo Ortega (2020), embora se possam encontrar formas primitivas de balões em manuscritos medievais do século $\mathrm{X}$, a primeira publicação do tipo atual pareceu em 1896, no jornal New York World com o personagem Yellow Kid. Desde então começou a se popularizar escritas dentro de balões acompanhando histórias em quadrinhos. Todavia, a depender do estilo do autor, os balões podem ser dispensados, ocorrendo a escrita ou um ícone em qualquer parte do quadrinho ou da página.

Nesse tipo de publicação, em geral, a linearidade da escrita alfabética é menos importante do que outros elementos de destaque. No caso específico das histórias em quadrinhos(HQ), o texto que aparece continuou sendo sempre linear para permitir uma leitura lógica. Porém, os ruídos e outros tipos de ação sempre tiveram a liberdade de ocorrer em qualquer parte do quadro, aparecendo onde fosse mais adequado. Sua leitura, portanto, sempre foi independente do texto, sobretudo da linearidade do texto. Trata-se apenas de uma informação a mais que se junta ao texto. 
Chamei de "escrita do barulho" (CAGLIARI, 1993) um tipo de escrita representada através de diferentes fontes de letras que usa o princípio acrofônico do alfabeto (CAGLIARI, 1989; 1993) para que a representação seja decifrável pelo leitor. Um termo tradicional para esse tipo de palavra é onomatopeia (LUYTEN, 2000). Justamente por essa razão, línguas diferentes costumam representar os mesmos sons com escritas diferentes. Diferentemente das interjeições, que têm uma forma ortográfica estabelecida, a representação do ruído ou da ação através da escrita apresenta, quanto muito, uma tradição, não uma forma ortográfica, como as demais palavras.

Exemplo: diferentes representações para o latido de cachorro (MEDEIROS, 2008):
Português: au-au
Francês: wou, ouuu
Inglês: gnaf-gnaf
Russo: vau, oouu

\section{MARCADORES PROSÓDICOS EM TEXTOS}

Certamente, as interjeições vieram da necessidade de se enfatizar algumas mensagens. Como a escrita não representa muitas coisas do contexto em que as falas acontecem, nem dos sentimentos e expectativas do autor do autor (CAGLIARI, 2016) ou dos personagens em narrativas, a escrita literária tradicionalmente tem lançado mão de expressões prosódicas, como: ele disse; ela falou consternada; João respondeu baixinho; ele gritou... entre outros. Chamei esses tipos de palavras de marcadores prosódicos da escrita (CAGLIARI, 1989; 1993). O uso desse tipo de palavras tornou as narrativas mais interessantes e atraentes. A indicação das mudanças de turno conversacional juntamente com razões emocionais (respondeu chorando...) fez das narrativas uma obra literária menos lógica e mais humana. Passar da descrição das emoções (chorando...) para os sons dessas emoções foi um caminho curto, fácil e previsível: em vez de dizer chorando, passa-se a dizer Buah! Buah!... Hoje, há um uso muito generalizado de expressões que denotam ruído, ações e sentimentos.

A dicionarização das interjeições aconteceu quando elas foram encontradas em bons autores. Na prática, as expressões que denotam emoções foram as privilegiadas. Essas expressões dependem basicamente do estado de espírito dos interlocutores. Expressões que denotam ruído e que dependem da ação ficaram confinadas a palavras dos marcadores prosódicos da escrita (disse, gritou, falou raivoso...). Essa situação durou até que começaram a aparecer outros tipos de "interjeição", como a representação de ruídos pelos sons que são ouvidos e interpretados, não pelo modo como eles poderiam 
ser descritos por palavras da língua.

Nas obras literárias, encontram formas dos marcadores prosódicos, sobretudo, nos diálogos. Porém, a ocorrência de expressões que denotam ruído está praticamente ausente, uma vez que os autores preferem descrever os efeitos da ação ao invés de representá-los de forma icônica. Se alguém ri de outrem, o autor diz fulano riu às gargalhadas e não transcreve as gargalhadas como Rarará (A Internet tem formas próprias, como Kkkkk, etc.). Esse tipo de escrita é raro, mas foi encontrado, por exemplo, na obra A Ilha do Dia Anterior de Umberto Eco, na seguinte passagem:

Estava em Casale: diante dele, a armada espanhola, com o barulho de seus carros, o bater das armas, as vozes de tenor dos castelhanos, o vozerio dos napolitanos, o áspero grunhido dos lansquenetes, e, ao fundo, alguns sons de trombeta que chegavam abafados, e os baques abrandados de alguns tiros de arcabuz, cloc, pof, taa-pum, como os fogos de artifício de uma festa do santo padroeiro (EDITORA RECORD, 1995, p. 26).

Observando o comportamento linguístico de crianças, sobretudo quando estão brincando, encontramos um uso frequente e criativo de expressões orais que se referem a ruídos. Os brinquedos se movimentam com uma trilha sonora correspondente ao barulho que as crianças imaginam que as coisas verdadeiras fazem na vida real. Mas o uso dessas expressões não se restringe às brincadeiras. Não é raro encontrar crianças que contam histórias, recheando-as de expressões que denotam ruídos. A sociedade e, sobretudo, a escola irão, depois, mostrar às pessoas que esses modos de falar devem ser evitados. É uma pressão social e cultural, controlando os usos da linguagem.

Nos dias de hoje, não se pode deixar de lado a Internet com seus modos de comunicação. A transferência das HQs para as redes sociais é um fato bem claro. O uso da linguagem em vídeos, em mensagens e, principalmente, nos WhatsApp, trouxe uma liberdade de escrita muito peculiar que chega, às vezes, ao absurdo não só nos conteúdos, como também nas formas de escrita e de expressão. Essa questão merece um estudo detalhado, que não será feito aqui.

Historicamente, vemos que o uso da linguagem oral sempre teve muita liberdade no uso de palavras e de expressões que eram evitadas em falas formais e na escrita. As interjeições furaram esse bloqueio, introduzindo onomatopeias em cantigas infantis e em narrativas. No século XIX, vieram as charges e os desenhos incentivaram o uso de expressões mais comuns na fala diária do que em textos de publicação. A representação acusticamente icônica de barulhos e ruídos através de vogais e de consoantes acabaram 
criando palavras de uso geral nas charges e, depois, nas histórias em quadrinhos, nas tirinhas humorísticas, acabando encontrando um lugar próprio e exato nas revistas em quadrinhos (HQs). Com as inúmeras possibilidades de comunicação trazidas pela Internet, nos últimos anos, cresceu enormemente o número de interações entre pessoas conhecidas e desconhecidas, via redes sociais (WhatsApp, YouTube, Instagram, sites/sítios, entre outros). O que foi um dia restrito às obras cinematográficas de especialistas, passou a ser domínio público. Obviamente, os modos de fazer dos aventureiros com iniciativa não são os mesmos dos profissionais. Assim, encontramos nas redes sociais um processo de reorganização da imagem, do som e do texto linguístico que ainda está em fase de expansão e de fixação para o futuro, como obra de arte ou não.

As histórias em quadrinhos (HQs) contribuíram de modo decisivo para a aceitação de um modo novo de ver a comunicação, de contar histórias, de ensinar, entre outros. Algumas obras literárias passaram a ser editadas na forma de historinhas em quadrinhos, pelo apelo que essa forma de divulgação e de aceitação passou a ter a partir do no último século. As histórias em quadrinhos, os mangás, e revistas semelhantes, algumas com fotos e não com desenhos (Grande Hotel, Sabrina, entre outros), trouxeram para a escrita muitos dos elementos que eram deixados de lado, porque a escrita convencional baseia-se apenas em letras com alguns poucos sinais de pontuação para facilitar a leitura.

\section{TIPOS DE REPRESENTAÇÃO DA ESCRITA QUE SE REFERE A RUÍDOS}

Como fazemos com as categorias gramaticais, subdividindo-as em itens com características próprias, algo semelhante pode-se fazer com a categoria das palavras que se referem a ruídos, ações e sentimentos na forma de onomatopeias. Por outro lado, como temos uma ortografia com regras precisas, toda inovação acaba gerando um problema, que deve ser entendido e, eventualmente, resolvido. Ou seja, escrever palavras sem seguir a ortografia oficial da língua vai ser um problema que, para uns é irrelevante, menor, e para outros, mais preocupados com a defesa da língua, um problema que deve ser corrigido como se fosse um erro de gramática.

Seguem os itens organizados de acordo com características comuns:

\section{INTERJEIÇÃO E ONOMATOPEIAS}

O primeiro grupo refere-se à escrita de algumas interjeições de uso comum e tradicional que acabaram ficando fixas em formas ortográficas dicionarizadas. É o caso de 
exemplos como: ah!, au-au!, upa!, oba, oh!,ufa!, entre outros. Essas expressões costumam vir escritas com ponto de exclamação no fim. Aqui, já encontramos o primeiro problema com a ortografia. Em português, a letra $\mathrm{H}$ depois de vogal só ocorre em interjeições (Ah!, Oh!), mostrando mais uma vez a função de coringa dessa letra no alfabeto latino, preenchendo funções diversas da simples representação de vogais e consoantes (CAGLIARI, 2009, 2015). A partir de conhecimentos dialetais, podemos dizer que uma expressão como há-há-há! oposta à Rarará!/rá-rá-rá, certamente indica um falante que usa o som de [h] em contextos em que outro tipo de falante usa o som de [r] em palavras como rua, rio, mar, amor, etc. Em uma escrita do tipo a-há!..., a letra H representa o que comumente é representado pela letra $\mathrm{R}$, nas palavras comuns da língua, como em caro, roda. A risada tem, ainda, formas novas de representação, típicas da Internet, como: hsuahsauahaua, kkkkkk.

Como dito anteriormente, há variações no modo como os ruídos são interpretados em diferentes línguas (cachorro: gnaf / au-au) ou mesmo em diferentes dialetos (MEDEIROS, 2000).

\section{A TRANSCRIÇÃO}

O segundo problema das escritas que representam ruídos, ações e emoções é como será a transcrição dos sons através de letras para permitir um reconhecimento do que se quer informar. A ortografia tradicional encontra aqui sérias dificuldades para incorporar formas de escrita não usuais no sistema ortográfico. Quando existe uma palavra na língua que é usada como interjeição dicionarizada, a solução é manter a forma escrita ortográfica. Assim, escrevemos, por exemplo, minha nossa!, miau (cf. o verbo miar), meu deus, entre outras. O uso não literário pode, contudo, preferir uma transcrição mais fonética à ortográfica, baseando-se em variedades dialetais. É o caso de Virge Maria!, em vez de Virgem Maria!. É provável que esse uso, sobretudo em expressões de origem religiosa, procure retirar o compromisso religioso da expressão, marcando-a como leiga.

Em outros casos, a transcrição cria uma forma baseada nas regras que orientam a leitura em formas ortográficas da língua, como nos exemplos: au-au, tigum!, trim trim!. Quando as crianças estão aprendendo a escrever e ainda não sabem a ortografia, já são capazes de transcrever palavras pela simples observação dos sons e dos conhecimentos das relações alfabéticas entre letras e sons, escrevendo, por exemplo, bixo (bicho), cacha (caixa), (CAGLIARI, 1998). Pessoas com pouco conhecimento da escrita das palavras, em caso de necessidade, agem do mesmo modo. No caso da escrita que representa ruídos 
e ações, a pessoa costuma fazer o mesmo dos alfabetizandos.

Formas escritas como tigum, tchigum também podem representar formas variantes por influência de diferenças fonológicas entre dialetos.

\section{ESTRANHAMENTO ORTOGRÁFICO}

O terceiro tipo de problema que a escrita que representa ruídos traz para o sistema é o aparecimento de uma transcrição que não corresponde às regras da ortografia. Neste caso, é o valor fonético atribuído às letras do alfabeto, isto é, um princípio acrofônico que comanda a forma da escrita (CAGLIARI, 2015, p. 122-132), como em: crac!, créc!, tchigum!, nhóc!, slap!, póing!, fon-fon! Como não podia deixar de ser, mesmo nestas formas de escrita, pode-se constatar como o conhecimento da ortografia, definindo a forma escrita das palavras da língua, orienta os valores fonéticos que as letras têm (CAGLIARI, 1998).

A ortografia não é uma transcrição fonética, mas ajuda a leitura por ser um sistema de base acrofônica, em princípio. O objetivo da ortografia é permitir a leitura. Isso significa que cada leitor da língua vai ler o que está ortograficamente escrito dizendo as palavras em seu próprio dialeto. Uma vez diante de uma escrita que representa ruídos, ele vai interpretar o som do ruído a seu modo. Todavia, por esse tipo de escrita estar mais próxima do princípio alfabético (acrofonia), a representação sonora das palavras fica mais clara para o leitor.

\section{NOVOS PADRÕES DE ESCRITA}

Um quarto tipo de problema na representação escrita de ruídos e barulhos está na combinação de letras formando padrões não previstos pela ortografia, como o aparecimento de repetição de letras para resultar em uma ênfase do que se quer representar. Assim, uma simples interjeição, ah!, por exemplo, pode ficar aaaah! ou, ainda, aaaaaahhhh!!!. O ruído de uma campainha passa de um simples trim para um triiimmmm. As repetições de letras não costumam passar de quatro ou cinco ocorrências. Essas são escritas com a intenção prosódica de aumentar o volume, a intensidade e a duração da fala, chamando a atenção do leitor. 


\section{EMPRÉSTIMOS}

Assim como a escrita tradicional a incorporação de palavras de outras línguas, cria problemas de ortografia: essas palavras estrangeiras serão escritas conforme a ortografia na língua original ou com uma escrita adaptada às regras ortográficas da língua que recebe o empréstimo? Trata-se de um problema um tanto complicado. Empréstimos costumam aparecer mais frequentemente em histórias em quadrinhos. Muitas dessas histórias são traduções e as escritas originais nem sempre facilitam a leitura em português.

Sem dúvida alguma, o mais comum é encontrar palavras do sistema de escrita do inglês. Algumas histórias em quadrinhos são reproduzidas sem nenhuma modificação por razões tipográficas. E as palavras permanecem conforme o original. As revistas do Batman e até os filmes para televisão dessa série não adaptaram as escritas dos ruídos, mantendo a forma inglesa de representá-los: criiinchh, crunch, skrashhh!, pow!. A influência dessas formas de representação é, às vezes, encontrada até em tirinhas feitas por brasileiros ou mesmo em revistas em quadrinho. Nas histórias de Garfield, do cartunista Jim Davis, também é comum encontrar a forma inglesa de escrita, como em smooch, click!, splat!, WHOP!, gulp, etc. O mesmo acontece com outras tiras traduzidas. Por exemplo, junto com o desenho de uma flecha atingindo Hagar (de Dik Browne) vem a escrita Thok. Aos poucos, vamos encontrando esse tipo de palavra em dicionários, como aconteceu com a palavra click, que hoje é muito usada.

\section{PALAVRA VELHA E PALAVRA NOVA}

Numa história de Garfield, no momento em que o personagem principal empurra o cachorro, seu companheiro (Odie), aparece na cena a palavra push (que significa empurrar) sobre a mão que empurra. Em outra tira, também de Garfield, aparece o personagem com a mão na boca e a palavra burp (que significa arrotar). Ou, ainda, em outra de suas tiras, aparece kick (isto é, chutar) e, no quadro seguinte, aparece o cachorro, assustado, passando por cima da cabeça de seu dono (foi chutado!).

Esse tipo de representação através de palavras tradicionais da língua é uma forma peculiar nas histórias em quadrinho, mas funciona bem. O problema da tradução, porém, continua e nem todo leitor conhece a língua de origem. 


\section{INVENTAR PALAVRA}

Às vezes, em vez de usar os recursos apontados acima, o autor resolve inventar uma palavra. $\mathrm{O}$ risco de não ser compreendido sempre existe. $\mathrm{O}$ contexto do quadro, as figuras que aparecem e um certo conhecimento de mundo do personagem, ajudam no entendimento do significado. Em princípio, esse tipo de palavra seria considerado uma palavra sem sentido, porque não registrada na língua. Um exemplo é a palavra: sputo (ao cuspir), que é uma ação com fortes conotações e que aparece junto com a figura de alguns personagens de tirinhas de jornal. Esse tipo de palavra não é copiado por outros cartunistas.

\section{ESCRITA FIGURATIVA}

Um dos recursos mais antigos da escrita é juntar desenhos para ajudar a interpretar o sentido de certas palavras. Esse procedimento era comum na escrita egípcia antiga, acompanhando certas palavras (DAVIES, 1996; DANIELS; BRIGHT, 1996; CAGLIARI, 2009). No mundo moderno, com as pichações, as mensagens em muros pelas cidades e um aumento na correspondência entre pessoas, o uso de representações figurativas, como coração, para representar as palavras amor, amizade, tornou-se muito comum.

Um procedimento semelhante é frequentemente encontrado em histórias em quadrinhos do tipo tirinha de jornal. Trata-se de uma representação gráfica de elementos não linguísticos, através de formas próprias icônicas ou figurativas. Assim, se alguém canta ou assobia uma canção, aparecem notas musicais para indicar tal fato. Se alguém está fortemente apaixonado, aparece um coração pulsante, etc. Uma forma especial surge quando desenhos representam idéias metafóricas usadas na linguagem comum. Por exemplo, alguém recebe um soco e vê estrelas; alguém está furioso e aparecem desenhos de cobras e lagartos. Outra forma ligeiramente diferente é a representação da falta de idéias através de rabiscos, raios e estrelinhas. Por exemplo, em uma publicação que mostrava um alienígena que falava uma língua não terrestre, a representação de sua fala era feita através de rabiscos à modo de letras. Isto pode ser observado também em filmes de ficção científica. Dentro desta categoria, podem ser encaixadas, também, escritas com letras que não representam nem palavras nem ruídos. Essas escritas aparecem somente para mostrar a impossibilidade de traduzir em palavras tudo o que o personagem gostaria de dizer. 
Com as escritas inventadas, surge um novo problema de escrita. Todo pensamento tem que passar pela linguagem oral, mesmo vindo de uma leitura. Portanto, todas essas formas gráficas inventadas devem ser entendidas através de um discurso mental com palavras da linguagem oral, necessitando, às vezes, sendo expressas por uma sentença ou até mesmo por um pequeno texto explicativo. Essa liberdade de uso de figuras para representar palavras ou mesmo sentenças em processos de comunicação levou a escrita das redes sociais modernas ao uso dos ícones de vários tipos e formas. Hoje, há um uso muito difundido desse tipo de material comunicativo. Na verdade, a representação figurativa ao lado da escrita alfabética vem desde os hieróglifos egípcios, como dito acima. Assim como antigamente, a escrita com ícones tem duas funções: uma representar uma palavra figurativamente; outra ajudar na decifração do que está escrito.

Vivemos num mundo de múltiplas formas de escrita. O alfabeto predomina nos textos publicáveis, mas fora desse contexto, o mundo dos ícones está cada vez mais presente, seja nos computadores, nas revistas em quadrinhos e, sobretudo, na Internet. Apesar da importância do estudo dessas formas de escrita e de leitura, a escola tradicional cuida apenas da escrita com letras. É preciso mudar essa atitude de ensino.

\section{A QUESTÃO LINGUÍSTICA}

Do ponto de vista da gramática de uma língua, nenhuma dessas palavras que representam ruídos, ações e sentimentos de formas figurativas ou icônicas tem um status definido no sistema das línguas, de acordo com uma visão tradicional de como deve ser o sistema de uma língua. Nesse sentido, é muito difícil considerar as interjeições e as onomatopeias como itens lexicais normais. Essas são palavras à margem da língua e, portanto, fora dos âmbitos de uma gramática. Entretanto, assim como essas expressões trazem interessantes questões em relação aos sistemas de escrita e de leitura, da mesma forma podem contribuir para estudos específicos da Linguística. A liberdade de criação e de uso dessas expressões, sem dúvida alguma, depende de mecanismos linguísticos e de processos de escrita e de leitura de que o usuário dispõe e que o linguista pode investigar.

Algumas observações interessantes sobre a estrutura morfológica. De um modo geral, pode-se dizer que grande número de palavras que representam ruídos e ações são palavras monossilábicas, na forma única ou repetida, com ah! uih! rarará, fon-fon, blá blá blá e são pronunciadas num ritmo silábico (CAGLIARI, 2007, p. 134-160).

Nas formas mais próximas às da língua, nota-se uma tendência à ocorrência do acento na última sílaba, quando se trata de monossílabos repetidos, como em blá blá 
-blá, Rarará, fon-fon. No caso de dissílabos, o acento costuma cair na penúltima sílaba: lero-lero, lenga-lenga, seguindo uma regra geral de acentuação da fala do português. Em quadrinhos estrangeiros, a pronúncia original segue as regras da língua de origem. Quando aparecem palavras estrangeiras em quadrinhos brasileiros, os leitores costumam usar uma pronúncia abrasileirada. Formas compostas de mais de três sílabas não costumam aparecer. A criação de palavras novas segue as regras gerais da língua, privilegiando as formas mais comuns e com menos problemas em sua representação segmental e prosódica. $\mathrm{O}$ fato de se evitar proparoxítonas mostra como o Português trata este tipo de palavra com reservas.

Por outro lado, podem ser facilmente encontradas sequências de sons não contempladas pela fonologia da língua, pelo menos no que diz respeito à forma fonológica básica de vocábulos, como em top, crack, slap, vapt-vupt, tchum. Algumas formas escritas revelam questões de variação linguística, como manhê, paiê - formas variantes que ocorrem frequentemente em falas gritadas ou em pedidos, como vocativos. É curioso notar variações de escrita como tchigum e tigum. Como hoje é mais comum falar tch diante de $i$, a escrita tigum começou a aparecer, dispensando o ch da escrita mais antiga, que era mais fonética.

Por fim, o uso de certas expressões relativas a ruídos e barulhos tem se tornado tão comum na língua, ocorrendo como verdadeiros itens lexicais, por exemplo, ocupando o núcleo de um sintagma nominal. Provavelmente, muitas palavras de origem onomatopaica entraram na língua dessa forma. Depois, até geraram outras categorias gramaticais, como verbos e nomes. Uma palavra como chispa, obviamente, é uma onomatopéia e tem origem na escrita de um barulho (chisp). Hoje, é um item lexical que conta ainda com palavras derivadas do tipo chispar, chispada, chispante, chispear. A palavra ufanar está relacionada com ufano, que significa admiração, mas também tem o sentido de cansaço (hoje pouco usado). Será a origem desta palavra a expressão de sopro que hoje representamos como ufa! ?

Enfim, quando se sai da tradição escolar, a cultura popular usa a linguagem oral e escrita do modo como acha melhor e do jeito como consegue comunicar. A Internet tem ajudado as pessoas preconceituosas com relação à linguagem a serem mais democráticas.

Muitas expressões que representam ruídos, ações e sentimentos através de ícones aparecem na fala, mas não na escrita. É incrível como a escrita é minimalista. Uma pessoa, até por brincadeira, poderia acabar uma comunicação oral da forma apresentada a seguir, mas, dificilmente, acabaria um texto escrevendo tal coisa:

Num vapt-vupt, um pouco de blá-blá-blá, talvez até com uma lengalenga ou um lero-lero, nossa! chegamos ao fim, uai! Oba! Ufa! Tchau! 


\section{CONSIDERAÇÕES FINAIS}

Tempos modernos e novas tecnologias exigem novas ações escolares. Apesar de historicamente sempre ficar atrasada com relação à realidade do mundo, a pedagogia sempre procurou se renovar. Em épocas de grandes mudanças, a pedagogia demora muito para se reestruturar. Como estamos passando por profundas mudanças no modo de vida, devido às novas tecnologias digitais de hoje, renovar a pedagogia é um problema difícil de acontecer em curto prazo, devido ao modo tradicional de os educadores se fixarem em valores do passado. Apesar desse cenário educacional e apesar do que os educadores queiram ou não, gostem ou não, é inevitável a mudança que está em progresso no mundo de hoje. Quando apareceram os lápis de cor, as crianças os adoraram e passaram a escrever e a desenhar com linhas coloridas. A velha caneta de molhar ficou na lembrança dos velhos professores. As canetas esferográficas deixaram de lado a caligrafia do tipo Petrarca e surgiu a caligrafia escolar, aprendida na alfabetização, com linhas da mesma espessura e no formato vertical reto. Outras inovações trouxeram mudanças pedagógicas marcantes. $\mathrm{O}$ rádio, o gravador, a filmadora, o projetor e a televisão fizeram do ensino escolar algo inconcebível há pouco mais de um século antes do fim do século XX. Essas invenções contribuem ainda hoje para a prática escolar e devem ser bem aproveitadas.

Os estudantes de hoje já não acham que o exposto acima seja novidade. Algumas coisas estão virando coisas de um passado remoto, do tempo dos pais ou dos avós. Hoje, há os computadores que, de enormes, tornaram-se tão pequenos que cabem nas mãos das crianças. Através dos celulares (smartphones), podem-se fazer coisas inimagináveis há dez anos. Com os recursos de comunicação que esses aparelhos têm, as crianças têm muito mais informação em casa do que qualquer aluno teria a dez anos nas melhores escolas. A inovação, aos poucos vira moda e todas as escolas passam a ter um nível de igualdade pedagógica. Até que surjam inovações revolucionárias. Estamos em tempos de ajustes. São tempos de pesquisa pedagógica e de uma nova filosofia da educação.

Vendo o desenvolvimento da comunicação escrita apresentado neste trabalho, a escola de hoje, desde o processo de alfabetização até a formação científica universitária, não pode ignorar os recursos dos computadores e, em particular, dos celulares. Vimos que, hoje, a comunicação das redes digitais incorporou textos de formatos tradicionais com formas figurativas, cheias de ícones, para melhorar a comunicação, para facilitar a interpretação do leitor, adequando-se às expectativas do escritor com relação aos seus leitores. E os leitores de hoje, mesmo acadêmicos e profissionais não são os mesmos de duas décadas atrás (CAGLIARI, 2016). Apesar das aparências, é um engano pensar que 
a comunicação como se apresenta hoje é melhor, mais clara e mais fácil para o leitor ou mesmo para o autor. Por trás de toda comunicação, há um processo cognitivo que precede e que orienta a forma de expressão. Não é o computador que faz a mente dos usuários; pelo contrário, são os usuários de decidem e que definem o que os computadores podem fazer.

Portanto, cabe à escola fazer as escolhas certas de tudo o que o mundo digital pode oferecer, para realizar uma boa educação. O uso de ícones não destrói o modo de pensar que era criado a partir de textos só com letras. Assim como a escrita literária, outros tipos de informação e de comunicação, como os vídeos, os filmes, as revistas em quadrinhos devem aparecer vivos na sociedade, todos são muito importantes e servem para diferentes finalidades. Os recursos digitais atuais produzem manifestações artísticas e culturais diferentes das de antigamente e estão mais abertos à iniciativa criativa das pessoas. A escola tem, hoje, à sua disposição, um mundo novo cheio de coisas maravilhosas, por exemplo, para alfabetizar e para ensinar ciência e tecnologia. Essa revolução no uso da imagem e dos novos processos de interação, sem dúvida alguma, vieram com as máquinas mas também contaram com as revistas em quadrinho, que substituíram o texto escrito com letras, com o texto com figuras e ícones. Hoje, a imagem, mais do que nunca, é a alma da comunicação humana. 


\section{REFERÊNCIAS:}

CAGLIARI, L. C. Marcadores prosódicos da escrita. In: Estudos Lingüísticos, XVIII Anais de Seminários do Gel. Lorena; Grupo de Estudos Linguísticos do Estado de São Paulo. p. 195-203. 1989.

CAGLIARI, L. C. A escrita do barulho. In: Estudos Lingüísticos XXII - Anais de Seminários do Gel. Ribeirão Preto: Instituição Moura Lacerda. p. 615-622. 1993.

CAGLIARI, L. C. Elementos de Fonética do Português Brasileiro. São Paulo: Editora Paulistana. 2007.

CAGLIARI, L. C. A História do Alfabeto. São Paulo: Editora Paulistana. 2009.

CAGLIARI, L. C. Alfabetizando sem o BÁ-BÉ-BI-BÓ-BU. São Paulo: Editora Scipione. 1998.

CAGLIARI, L. C. Sobre uma teoria da expectativa. In: Scripta. Belo Horizonte: PUCMG. v. 20-38. p. 382-408. 2016.

CAMARGO, S. C.; RIVELINI-SILVA, A. C. Histórias em quadrinhos no ensino de ciências: um olhar sobre o que foi produzido nos últimos doze anos no ENEQ e ENPEC. Revista ACTIO: Docência em Ciências. v. 2, n. 3. 2017. Disponível em: <https:// periodicos.utfpr.edu.br/actio/article/view/6818>. Acesso em: 10 jan. 2020.

DANIELS, P.; BRIGHT, W. The world's writing systems. Oxford: Oxford University Press. 1996.

DAVIES, W. V. Os hieróglifos egípcios. In: Lendo o Passado: do cuneiforme ao alfabeto. A história da escrita antiga. São Paulo: Edusp; Ed. Melhoramentos. pág. 94-173. 1996.

DINGEMANSE M.; TORREIRA F.; ENFIELD NJ. Is "Huh?" a Universal Word? Conversational Infrastructure and the Convergent Evolution of Linguistic Items. PLoS ONE 8(11), 2013. Disponível em: <https://doi.org/10.1371/journal.pone.0078273>. Acesso em: 10 jan. 2020.

ECO, Umberto. A Ilha do Dia Anterior. São Paulo: Editora Record. 1995.

IPA. Alfabeto fonético internacional. Disponível em: <https://pt.wikipedia.org/wiki/ Alfabeto_Fon\%C3\%A9tico_Internacional>.Acesso em: 10 jan. 2020.

LUYTEN, M. B. A estética das onomatopeias. 2000. Disponível em: <http://www. 
portcom.intercom.org.br/pdfs/e721bf44f30ff5ecb58ca7e3b63b2286.pdf > . Acesso em: 11 jan. 2020.

MASSINI-CAGLIARI, G.; CAGLIARI, L. C. Diante das Letras: a escrita na alfabetização. Campinas: Mercado de Letras. 1999.

MASSINI-CAGLIARI, G.; CAGLIARI, L. C. Fonética. In: MUSSALIM, F.; BENTES, A. C. (Orgs.). Introdução à Lingüistica: domínios e fronteiras. São Paulo: Editora Cortez. p. 105-146. 2001.

MEDEIROS, J. P. S. Onomatopeias em outras línguas. 2008. Disponível em: $<$ http:// tecidotextual.blogspot.com/2008/02/onomatopias-em-outras-lnguas.html>. Acesso em: 06 jan. 2020.

MONTEIRO LOBADO. Sítio do Pica-Pau Amarelo. 23 obras publicadas entre 19201947. Várias editoras. As Reinações de Narizinho. Ed. Monteiro Lobato e Cia Editora Nacional. 1931. Disponível em: <https:/pt.wikipedia.org/wiki/S\%C3\%ADtio_do_ Picapau_Amarelo>.Acesso em: 10 jan. 2020.

MOUlTON, C.; MARSTON, E.; PETER, H. G. Wonder Woman \#1. 1942. Disponível em: <https://pt.wikipedia.org/wiki/Mulher-Maravilha>. Acesso em: 10 jan. 2020.

ORTEGA, R. Disponível em: < https://super.abril.com.br/cultura/descubra-a-origem-dobalao/> Acesso em: 06 jan. 2020.

PACHECO, V. Investigação fonético-acústica e experimental dos sinais de pontuação enquanto marcadores prosódicos. Dissertação (mestrado em Lingüística). Instituto de Estudos da Linguagem, Unicamp, Campinas: 2003.

PACHECO, V. O efeito dos estímulos auditivo e visual na percepção dos marcadores prosódicos lexicais e gráficos usados na escrita do português brasileiro. Tese de Doutorado (em Lingüística). Instituto de Estudos da Linguagem, Unicamp, Campinas: 2006.

SAUSSURE, F. de. Curso de Linguística Geral. São Paulo: Ed. Cultrix. $2^{\text {a }}$ Ed. 1999.

$<$ http://www.guiadosquadrinhos.com/revistas-mais-desejadas> Acesso em 09 jan. 2020. (Sandman de Neil Gaiman; Homem Aranha; Mulher Maravilha; O Fantasma; Tarzan).

$<$ https://loja.panini.com.br/panini/vitrines/comics-panini-books.aspx $>$ Acesso em: 10 jan. 2020. (HQs modernas). 